\title{
Correlation between polymorphisms in the estrogen receptor $\alpha$ gene and coronary heart disease: A meta-analysis
}

\author{
W. Zhou ${ }^{1 *}$, K.H. He ${ }^{2 *}$ and M.H. Chen ${ }^{1}$ \\ ${ }^{1}$ Department of Cardiology, Central Hospital of Wuhan, Wuhan, China \\ ${ }^{2}$ Department of Cardiology, Tongji Hospital, Tongji Medical College, \\ Huazhong University of Science and Technology, Wuhan, China \\ *These authors contributed equally to this study. \\ Corresponding author: M.H. Chen \\ E-mail:wzhou887@126.com
}

Genet. Mol. Res. 15 (3): gmr.15037835

Received January 15, 2016

Accepted May 17, 2016

Published September 16, 2016

DOI http://dx.doi.org/10.4238/gmr.15037835

Copyright (C) 2016 The Authors. This is an open-access article distributed under the terms of the Creative Commons Attribution ShareAlike (CC BY-SA) 4.0 License.

\begin{abstract}
The aim of this study was to conduct a systematic evaluation the correlation between polymorphisms in the estrogen receptor $\alpha$ gene $(E S R \alpha)$ and coronary heart disease susceptibility. Casecontrol studies until August 2015 analyzing the correlation between the ESR $\alpha$ PvuII T/C polymorphism and coronary heart disease were obtained from various electronic databases (CBM, CNKI, Wanfang Data, VIP, and MEDLINE, Cochrane Library, Embase, Springer, and Ovid. The data obtained from these studies were evaluated and valid data was extracted. A meta-analysis was performed using RevMan 5.0. Eleven cases, comprising 1742 patients with coronary heart disease and 2012 controls, that conformed to the inclusion criteria set in this study were extracted. The results of our meta-analysis indicated that the $\mathrm{C}$ and $\mathrm{T}$ alleles, the $\mathrm{TC}+\mathrm{CC}$ and $\mathrm{TT}$ genotypes, and the $\mathrm{CC}$ and $\mathrm{TT}+\mathrm{TC}$
\end{abstract}


genotypes did not differ significantly. The results of this meta-analysis confirmed that there was no correlation between polymorphisms in ESR $\alpha$ and coronary heart disease susceptibility in the Chinese population.

Key words: Estrogen receptor; Coronary heart disease; Meta-analysis; Gene polymorphism; ESR ; PvuII polymorphism

\section{INTRODUCTION}

Epidemiological and laboratory studies have confirmed that estrogen has a protective effect on the cardiovascular system (Jia et al., 2015; Vuorinen et al., 2015). Estrogen protects against atherosclerosis by influencing lipoprotein metabolism, or by directly acting on blood vessels (Aggarwal et al., 2012; Davey, 2012). Since estrogen function is mediated by the estrogen receptor (ESR), and polymorphisms in ESR are correlated with the expression and function of ESR (Kishi et al., 2009), polymorphisms in ESR may influence the effect of estrogen on atherosclerosis (Lehtimäki et al., 2002; Mansur et al., 2005). The PvuII, $X b a \mathrm{I}$, and Bst UI polymorphisms in ESR $\alpha$ have been commonly observed in the population (Zhang et al., 2005). The PvuII and XbaI polymorphisms are point mutations located at the amino-terminal primary transcription functional domain of intron 1. These polymorphisms may influence the expression and function of ESR $\alpha$. Different ESR $\alpha$ genotypes may result in inter-individual differences in their expression and function, which could further influence the biological effect of estrogen in vivo.

The PvuII polymorphism, which occurs at a common mutation site, is one of the most common polymorphisms in ESR $\alpha$. However, single nucleotide polymorphisms (SNPs) in $E S R \alpha$ are considerably different in populations belonging to different ethnicities and geographical locations; therefore, the results of domestic and international studies, and even those conducted in populations from various geographic regions belonging to the same ethnic group, are quite inconsistent. Recently, Jiang et al. (2015) conducted a meta-analysis to determine the correlation between ESR $\alpha$ polymorphisms and cardiovascular disease (CVD) and reported that the two were not associated. Therefore, the association between ESR $\alpha$ polymorphisms and CVD remains to be elucidated. This meta-analysis attempted to clarify the correlation between the $P v u \mathrm{II}$ T/C polymorphism in ESR $\alpha$ and coronary heart disease using related case-control studies. Additionally, the relationship between mutations in the estrogen receptor gene and coronary heart disease susceptibility was evaluated.

\section{MATERIAL AND METHODS}

\section{Inclusion criteria}

Case-control studies analyzing the association between the $P v u I I$ T/C polymorphism in ESR $\alpha$ and coronary heart disease and published in Chinese or English were selected for this study. Studies were not excluded on the basis of the ethnicity of the subjects. However, similar standards of analytical methods, diagnostic criteria, and control groups were maintained among the included studies. Moreover, the genotypes of the control groups conformed to the Hardy-Weinberg (H-W) equilibrium. If more than one study was based on the same sample population or contained similar data, the study with the larger sample size was selected.

Genetics and Molecular Research 15 (3): gmr.15037835 


\section{Exclusion criteria}

Studies that did not focus on the PvuII locus in ESR $\alpha$ were excluded from this metaanalysis. Moreover, studies that adopted inappropriate statistical methods, or those that reported incomplete data, were excluded.

\section{Document retrieval}

The electronic databases CNKI, CBM, VIP, Wanfang Data, China Dissertation Database, MEDLINE, Cochrane Library, Embase, Springer, and Ovid were searched for relevant studies using the keywords "estrogen receptor", "gene polymorphism", "coronary heart disease", and "ischemic cardiomyopathy". The references cited in the included studies were also retrieved. The document retrieval process was performed until August 2015.

\section{Quality assessment}

The quality of the included case-control studies was assessed for adequacy of sample size, definition of diagnostic criteria, condition of the group match, the comparability of the control group to the patient group, conformance of the control group genotype to the H-W equilibrium, rationality of the gene detection method, and data sufficiency, according to the Oxford Critical Appraisal Skill Program (Oxford CASP, 2004).

Data was independently extracted and cross-checked by two reviewers using a unified data extraction table. The corresponding author of an included study was contacted when required (or to confirm the specific implementation process). A third independent opinion was obtained in case of disagreements between the two reviewers regarding the data extraction process.

\section{Data analysis}

The genotype distribution of the $P v u I I$ T/C polymorphism in ESR $\alpha$ was determined by analyzing the H-W equilibrium. This meta-analysis was performed on the RevMan 5.0 software platform. The Z-test was performed to detect heterogeneity among the included studies. A fixed-effects model was used in the absence of any heterogeneity and a random effects model was selected to analyze the merged data in case of significant, non-clinical heterogeneity among the results. Odd's ratios (ORs) and their 95\% confidence intervals (Ci) were calculated using a two-tailed test; $\mathrm{P}=0.05$ was considered to be statistically significant. Publication bias in the included studies was evaluated by constructing funnel plots.

\section{RESULTS}

\section{Study characteristics}

The initial electronic search yielded 120 articles relevant to the study subject. Reviews, studies that did not analyze the $P v u$ II locus in ESR $\alpha$, and articles presenting incomplete data were excluded. As a result, 10 studies comprising 1742 patients with coronary heart disease and 2012 healthy controls, were included in this study (Guo et al., 2002; Huang et al., 2002; Zhang et al., 2002; Zheng et al., 2002; Cheng et al., 2006; Li et al., 2006; Xu et al., 2008; Tang et al., 2008; Jin et al., 2010; Shen et al., 2012). 
Quality analysis of the included studies $(\mathrm{N}=10)$ showed that all studies set clear diagnostic criteria and had a sufficient sample size. Moreover, the cases and control groups were comparable, the adopted gene detection method (polymerase chain reaction-restriction fragment length polymorphism; PCR-RFLP) was rational, and the obtained results were clear. Additionally, the genotypes of the control groups were in accordance with the H-W equilibrium in all studies. The specific genotypic distributions of the $P v u \mathrm{II}$ T/C polymorphism in ESR $\alpha$ in both cases and controls are summarized in Table 1.

Table 1. Characteristics of included studies.

\begin{tabular}{|c|c|c|c|c|c|c|c|c|c|c|c|}
\hline \multirow[t]{2}{*}{ Publications } & \multirow{2}{*}{$\begin{array}{c}\text { Published } \\
\text { year }\end{array}$} & \multirow[t]{2}{*}{ Ethnicity } & \multirow{2}{*}{$\begin{array}{l}\text { Genotyping } \\
\text { methods }\end{array}$} & \multirow[t]{2}{*}{ Group } & \multirow[t]{2}{*}{$\mathrm{N}$} & \multicolumn{3}{|c|}{ Genotypes } & \multicolumn{2}{|c|}{ Allele } & \multirow[t]{2}{*}{$\mathrm{H}-\mathrm{W}$} \\
\hline & & & & & & TT & $\mathrm{TC}$ & $\mathrm{CC}$ & $\mathrm{T}$ & $\mathrm{C}$ & \\
\hline \multirow[t]{2}{*}{ Guo et al. } & \multirow[t]{2}{*}{2002} & \multirow[t]{2}{*}{ Han } & \multirow[t]{2}{*}{ PCR-RFLP } & Case & 53 & 7 & 23 & 23 & 37 & 69 & \multirow[t]{2}{*}{ Yes } \\
\hline & & & & Control & 72 & 20 & 42 & 10 & 82 & 62 & \\
\hline \multirow[t]{2}{*}{ Huang et al. } & \multirow[t]{2}{*}{2002} & \multirow[t]{2}{*}{ Han } & \multirow[t]{2}{*}{ PCR-RFLP } & Case & 118 & 13 & 54 & 51 & 80 & 156 & \multirow[t]{2}{*}{ Yes } \\
\hline & & & & Control & 135 & 14 & 41 & 80 & 69 & 201 & \\
\hline \multirow[t]{2}{*}{ Zheng et al. } & \multirow[t]{2}{*}{2002} & \multirow[t]{2}{*}{ Han } & \multirow[t]{2}{*}{ PCR-RFLP } & Case & 54 & 6 & 30 & 18 & 42 & 66 & \multirow[t]{2}{*}{ Yes } \\
\hline & & & & Control & 51 & 7 & 35 & 9 & 49 & 53 & \\
\hline \multirow[t]{2}{*}{ Zhang et al. } & \multirow[t]{2}{*}{2002} & \multirow[t]{2}{*}{ Han } & \multirow[t]{2}{*}{ PCR-RFLP } & Case & 259 & 101 & 111 & 47 & 313 & 205 & \multirow[t]{2}{*}{ Yes } \\
\hline & & & & Control & 243 & 69 & 127 & 39 & 265 & 205 & \\
\hline \multirow[t]{2}{*}{ Cheng et al. } & \multirow[t]{2}{*}{2006} & \multirow[t]{2}{*}{ Han } & \multirow[t]{2}{*}{ PCR-RFLP } & Case & 190 & 38 & 85 & 67 & 161 & 219 & \multirow[t]{2}{*}{ Yes } \\
\hline & & & & Control & 200 & 43 & 92 & 65 & 178 & 222 & \\
\hline \multirow[t]{2}{*}{ Li et al. } & 2006 & Han & PCR-RFLP & Case & 80 & 21 & 36 & 23 & 78 & 82 & Yes \\
\hline & & & & Control & 165 & 33 & 88 & 44 & 154 & 176 & \\
\hline Xu et al. & 2008 & Han & PCR-RFLP & Case & 174 & 82 & 78 & 14 & 242 & 106 & Yes \\
\hline & & & & Control & 210 & 92 & 88 & 30 & 272 & 148 & \\
\hline
\end{tabular}

\section{Results of the meta-analysis}

\section{Recessive model}

The results of the heterogeneity test confirmed a statistical heterogeneity among the included studies $\left(I^{2}=70 \%, \mathrm{P}=0.0004\right)$; therefore, the random effects model was adopted for metaanalysis. The results of this analysis showed that populations expressing the TC and TT genotypes of $P v u \mathrm{II}$ T/C polymorphism were at an equal risk of developing coronary heart disease compared to those expressing the $\mathrm{CC}$ genotype $(\mathrm{OR}=1.15,95 \% \mathrm{CI}=0.84-1.58 ; \mathrm{P}=0.37]$ (Figure 1).

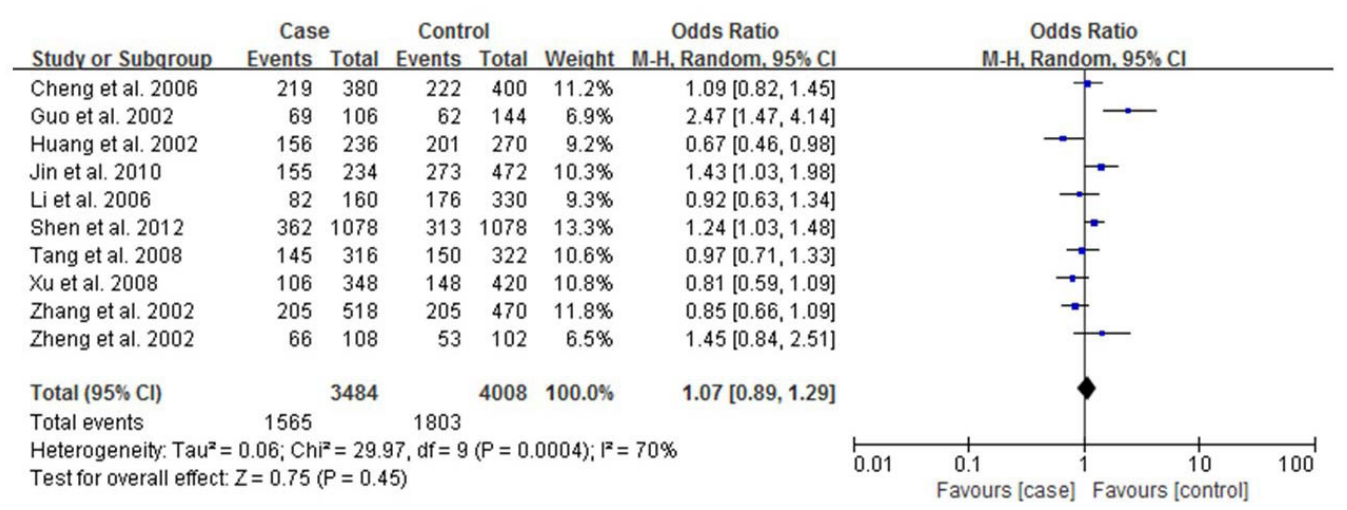

Figure 1. Forest plot of the correlation between coronary heart disease and the estrogen receptor- $\alpha(E S R \alpha) P v u I I$ $\mathrm{T} /$ Cpolymorphism using arecessive model (CC vs $\mathrm{TC}+\mathrm{TT})$.

Genetics and Molecular Research 15 (3): gmr.15037835 


\section{Dominant model}

The results of the heterogeneity test confirmed the presence of statistical heterogeneity among the included studies $\left(I^{2}=57 \%, \mathrm{P}=0.01\right)$; therefore, the random effects model was adopted for meta-analysis. The results of this analysis showed that populations expressing the TC and $\mathrm{CC}$ genotypes were at an equal risk of developing coronary heart disease as those expressing the TT genotype $(\mathrm{OR}=0.94,95 \% \mathrm{CI}=0.73-1.21 ; \mathrm{P}=0.66)$ (Figure 2$)$.

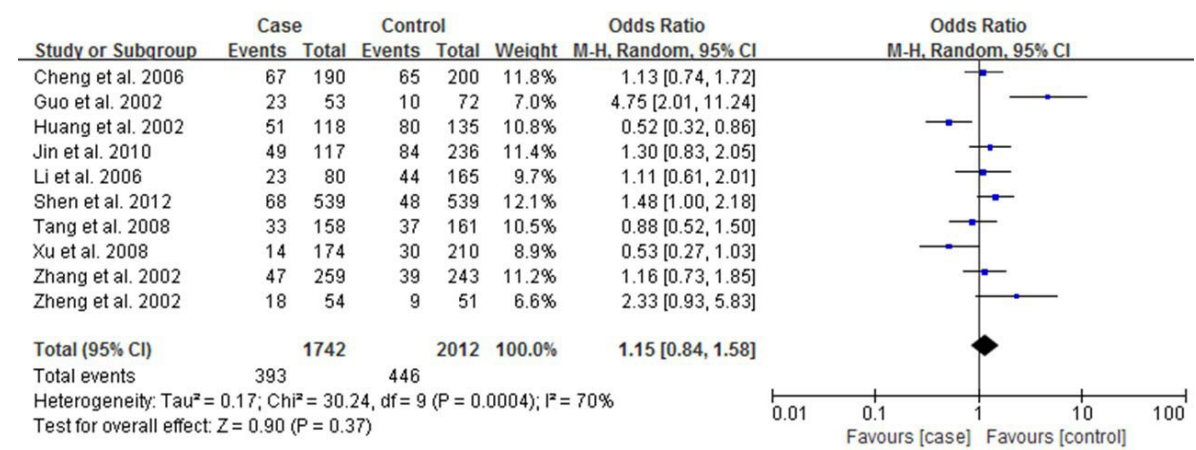

Figure 2. Forest plot of the correlation between coronary heart disease and the estrogen receptor- $\alpha$ (ESR $\alpha) P v u \mathrm{II}$ $\mathrm{T} /$ Cpolymorphism using adominant model (TT $v s \mathrm{TC}+\mathrm{CC})$.

\section{Allele comparison}

The results of the heterogeneity test confirmed a statistical heterogeneity among the included studies $\left(I^{2}=70 \%, \mathrm{P}=0.0004\right)$; therefore, the random effects model was adopted for meta-analysis. The meta-analysis was performed using the $\mathrm{C}$ allele as the exposure factor and the $\mathrm{T}$ allele as the non-exposure factor. The results showed that populations expressing the $\mathrm{C}$ allele were at an equal risk of developing coronary heart disease as those expressing the $\mathrm{T}$ allele $(\mathrm{OR}=1.07,95 \% \mathrm{CI}=0.89-1.29 ; \mathrm{P}=0.63)($ Figure 3$)$.

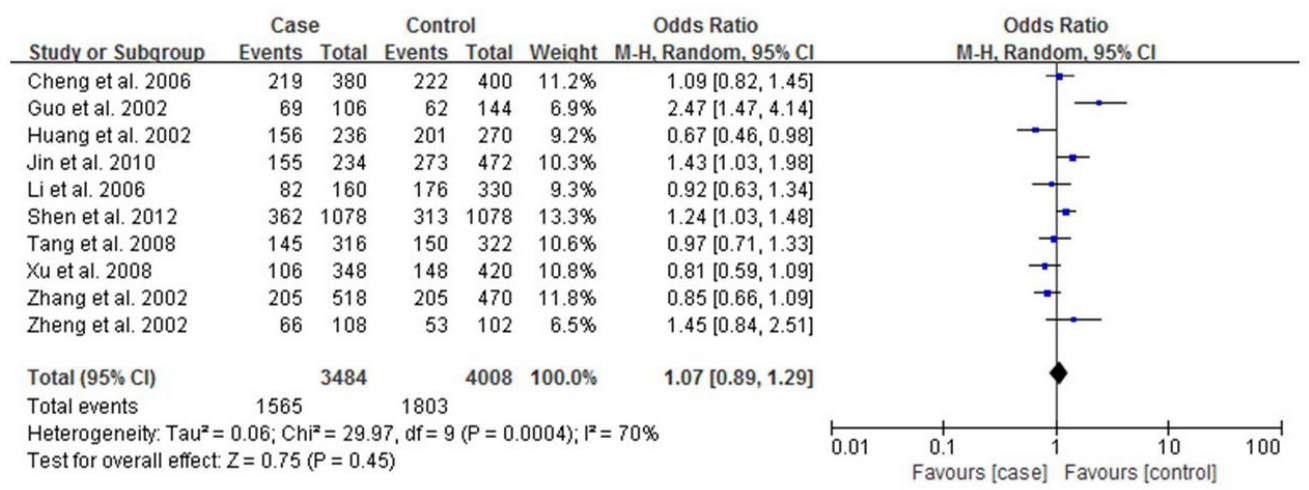

Figure 3. Forest plot of the correlation between coronary heart disease and the estrogen receptor- $\alpha(E S R \alpha) P v u I I$ $\mathrm{T} /$ Cpolymorphism (C allele $v s \mathrm{~T}$ allele).

Genetics and Molecular Research 15 (3): gmr.15037835 


\section{Evaluation of publication bias and sensitivity}

The funnel plots of the meta-analysis of the TC + CC vs TT genotypes, TC + TT vs $\mathrm{CC}$ genotypes, and the $\mathrm{C} v \mathrm{~T}$ alleles were symmetrical, indicating minor publication bias. The sensitivity analysis, performed by excluding individual studies, revealed no significant changes in the pooled OR, confirming that the meta-analysis was stable and reliable (Figure 4).



Figure 4. Funnel plot depicting possible publication bias.

\section{DISCUSSION}

ESR is a member of the ligand-dependent transcription factor superfamily that includes the steroid hormone, thyroid hormone, vitamin D3, and retinoic acid receptors. Human ESR $\alpha$ is located at chromosome 6q25.1; wild-type ESR $\alpha$ has a $\sim 140 \mathrm{~kb}$-long full-length sequence comprising 6322 nucleotide pairs, divided into 8 exons and 7 introns. From these nucleotide pairs, 1785 encode a protein comprising 595 amino acids (Zhang et al., 2005). The interaction between estrogen and its receptor (ESR) results in a dipolymer that combines with the estrogen receptor response element and stimulates transcription of its target genes. This, in turn, regulates growth, reproduction, and differentiation in the body, as well as the functions of its target tissues and organs, including the mammary tissue, uterus, vagina, ovary, sperm, bone tissue, liver, cardiovascular system, and the nervous system. Previous studies have reported a close association between the $P v u I I$ polymorphisms in ESR $\alpha$ and susceptibility to several diseases.

Ten case-control studies, comprising 1742 patients with coronary heart disease and 2012 controls, were included in this meta-analysis. The results of this analysis suggested that the ESR $\alpha$ $P v u I I$ T/C polymorphism was not significantly correlated to coronary heart disease susceptibility.

However, previous studies have provided conflicting accounts of the correlation between the ESR $\alpha$ PvuII T/C polymorphism and coronary heart disease susceptibility. These differences can be attributed to differences in the genetic backgrounds of different populations, the sample sizes, standards, ages, and genders of the subjects, as well as the family history of CHD.

The included studies adopted appropriate methods for genotype analysis; however, several differences were observed among individuals. Furthermore, the process for the 
verification of sequences obtained by PCR-RFLP differed in individual studies. These differences may lead to heterogeneity in the results of the meta-analysis. We could not identify any significant factors to stratify the data from the included studies; additionally, the number of studies included in this study was limited. Therefore, subgroup analysis was not performed. Therefore, future studies must exclude these confounding factors to determine the correlation between ESR $\alpha$ PvuII T/C polymorphism and coronary heart disease susceptibility.

The results of this study are subject to certain limitations that must be addressed in future studies. First, only articles published in Chinese and English were chosen for this meta-analysis, which may lead to a language bias. Additionally, the controls groups were not gender- and age-matched with the case groups in the included studies.

In conclusion, the correlation between the ESR $\alpha$ PvuII T/C polymorphism and coronary heart disease susceptibility was evaluated by a meta-analysis. The results of this analysis indicated that these factors were not significantly related. Because of the inclusion of a limited number of studies (and consequently, cases), the results of this analysis must be further validated by larger-scale studies with a strict design to ensure maximum control of all confounding factors, and with homogeneous cases and controls. Additionally, the gene-gene and gene-environment interactions must be analyzed to clarify the pathogenesis of coronary heart disease.

\section{Conflicts of interest}

The authors declare no conflict of interest.

\section{ACKNOWLEDGMENTS}

Research supported by grants provided by the National Natural Science Foundation of China (\#81300214 and \#81470482) and the Hubei province Natural Science Foundation (\#2013CFB378).

\section{REFERENCES}

Aggarwal S, Loomba RS and Arora R (2012). Preventive aspects in peripheral artery disease. Ther. Adv. Cardiovasc. Dis. 6: 53-70.http://dx.doi.org/10.1177/1753944712437359

Cheng AJ, Fu NK, Xu J, Wang M, et al. (2006). A study of the correlation between estrogen receptor gene polymorphism and coronary heart disease as well as serum lipid levels in postmenopausal women. Hebei Med. J. 28: 568-570.

Davey DA (2012). Update: estrogen and estrogen plus progestin therapy in the care of women at and after the menopause. Womens Health (Lond. Engl.) 8: 169-189. http://dx.doi.org/10.2217/whe.12.1

Guo ZG, Zheng H, Wu SZ, et al. (2002). Relationship between estrogen receptor gene polymorphism and coronary heart disease. Chin. J. Geriatr. Cardiovasc. Cerebrovasc. Dis. 4: 374-377.

Huang XZ, Zhang PA, Li Y, Xu M, et al. (2002). Association of estrogen receptor gene polymorphism with coronary heart disease. Chin. J. Cardiol. 30: 78-81.

Jia M, Dahlman-Wright K and Gustafsson JÅ (2015). Estrogen receptor alpha and beta in health and disease. Best Pract. Res. Clin. Endocrinol. Metab. 29: 557-568. http://dx.doi.org/10.1016/j.beem.2015.04.008

Jiang N, Yang G and Peng CL (2015). ESR1 gene polymorphisms PvuII (rs2234693T>C) and XbaI (rs9340799A $>$ G) may not be directly correlated with cardiovascular disease risk. Genet. Mol. Res. 14: 13932-13944. http://dx.doi. org/10.4238/2015.October.29.14

Jin LZ, Chen XC, Ma YD, SUN X, et al. (2010). Association of estrogen receptor $\alpha$ gene PvuII and XbaI polymorphisms with coronary artery disease. Zhongguo Shengwu Yixue Gongcheng Xuebao 16: 136-139.

Kishi T, Ikeda M, Kitajima T, Yamanouchi Y, et al. (2009). A functional polymorphism in estrogen receptor alpha gene is associated with Japanese methamphetamine induced psychosis. Prog. Neuropsychopharmacol. Biol. Psychiatry 33: 895-898.http://dx.doi.org/10.1016/j.pnpbp.2009.04.008

Genetics and Molecular Research 15 (3): gmr.15037835 
Lehtimäki T, Kunnas TA, Mattila KM, Perola M, et al. (2002). Coronary artery wall atherosclerosis in relation to the estrogen receptor 1 gene polymorphism: an autopsy study. J. Mol. Med. 80: 176-180. http://dx.doi.org/10.1007/ s00109-001-0311-5

Li LH, Zhao FM, Li GQ, et al. (2006). Association between estrogen receptor alpha gene variation and risks of cardiovascular disease. Mol. Cardiol. China 6: 90-94.

Mansur AdeP, Nogueira CC, Strunz CM, Aldrighi JM, et al. (2005). Genetic polymorphisms of estrogen receptors in patients with premature coronary artery disease. Arch. Med. Res. 36: 511-517. http://dx.doi.org/10.1016/j. arcmed.2005.04.002

Oxford CASP (2004). Critical Appraisal Skills Programme (CASP). Available at [https://www.guidelinesinpractice.co.uk/ nov_00_hibbert_casp_nov00].

Shen C, Chen J, Fan S, Li Z, et al. (2012). Association between the polymorphism of estrogen receptor $\alpha$ and coronary artery disease in a Chinese population. Eur. J. Intern. Med. 23: 175-178. http://dx.doi.org/10.1016/j.ejim.2011.05.006

Tang ZZ, Li XP and Yang JH (2008). Relationship of estrogen receptor $\alpha$ gene polymorphism and risk of cardiovascular diseases. Mil. Med. J. South China 22: 35-37.

Vuorinen A, Odermatt A and Schuster D (2015). Reprint of "In silico methods in the discovery of endocrine disrupting chemicals". J. Steroid Biochem. Mol. Biol. 153: 93-101.http://dx.doi.org/10.1016/j.jsbmb.2015.08.015

Xu H, Hou X, Wang N, Hui B, et al. (2008). Gender-specific effect of estrogen receptor-1 gene polymorphisms in coronary artery disease and its angiographic severity in Chinese population. Clin. Chim. Acta 395: 130-133. http://dx.doi. org/10.1016/j.cca.2008.06.004

Zhang Y, Xie RP and Jiang YH (2002). Correlation of estrogen receptor gene polymorphism and cerebral infarction. Chin. Med. J. (Engl.) 82: 1443-1446.

Zhang ZL, Qin YJ, He JW, Huang QR, et al. (2005). Association of Xba I, Pvu II, and Bst U I polymorphisms of estrogen receptor-alpha gene with bone mass in men. Zhonghua Yi Xue Yi Chuan Xue Za Zhi. 22: 447-449.

Zheng B, Zhang Z, Black CM, de Crombrugghe B, et al. (2002). Ligand-dependent recombination in fibroblasts: a potentially powerful technique for investigating gene function in fibrosis. Am. J. Pathol. 160: 1609-1617.

Genetics and Molecular Research 15 (3): gmr.15037835 